\title{
Critical Thinking of Ongoing Arguments about "the younger, the better" Hypothesis in Second Language Acquisition
}

\author{
Huaifei Huang \\ School of foreign Languages, Quanzhou Normal University \\ Fujian Province, China 362000 \\ figo6668@163.com
}

\begin{abstract}
Keywords: Second language acquisition, Critical period hypothesis, "The younger, the better" hypothesis.
\end{abstract}

\begin{abstract}
With some clear review of the previous studies on "the younger, the better" hypothesis, the article here attempts to summarize possible factors responsible for the ongoing arguments about this topic, and puts forward some items necessary for a more rational paradigm in further study.
\end{abstract}

\section{1. "The younger, the better" Hypothesis}

In 1950s Penfield and Roberts, on the basis of the different speech recovery in brain injury between children and adults, asserted that "for the purposes of learning languages, the human brain becomes progressively stiff and rigid after the age of nine" (1959: 236), and advocated early second language learning in life, saying "when languages are taken up for the first time in the second decade of life, it is difficult ...to achieve a good result" (1959: 255). Such hypothesis was later refined by Lenneberg, who argued that "language development ran a definite course on a definite schedule with an onset between the second and thirteen years of life" (1967:127). He claimed that the close of critical period coincides with the end of the development of cerebral dominance, after which the ability to learn a language naturally atrophies. From then on many researchers attempted to verify or falsify the Critical Period Hypothesis with its core notion of "the younger, the better" in language learning.

\section{The studies for and against "the younger, the better" hypothesis}

Lenneberg's hypothesis only originally included first language acquisition. However, due to the fact that there are rare individuals with first language deprivation, the test of the hypothesis turned to the context of second language acquisition. But, there has been much less of a consensus on "the younger, the better" hypothesis since it has been applied to second language acquisition. Many scholars reported their research findings from for-side or against-side to support or refute the Hypothesis, leaving it an ongoing topic in second language acquisition research.

The proponent group of the Hypothesis argue that children start to learn a second language within the critical period can attain successful achievements, whereas those outside of it will face more difficulties. Such researches, covering phonology, production and comprehension of morphology, and grammaticality judgments, showed a close relation between the onset age of learning and second language achievements. For instance, Asher and Garcia, 1969; Ramsey and Wright 1974; Seliger et al.'s 1975; Oyama, 1976; Patkowski, 1980; Williams, 1980; Piper and Cansin, 1988; Johnson \& Newport, 1989, 1991; Thompson, 1991; Hyltenstam, 1992; Flege and his colleagues, 1995, 1999; Weber-Fox and Neville, 1996; Kim, Relkin, Lee, and Hirsch,1997; DeKeyser, 2000, Wartenburger et al.,2003. These facts have often been taken as evidences for "the younger, the better" in second language learning.

By comparison, some of the opponent group of the Hypothesis seek to disprove the existence of maturational constraints by demonstrating ongoing age effects after the closure of critical period, for instance, Bialystok \& Miller, 1999; Birdsong \& Molis, 2001. Or native-like achievement reached by late starters, for example, Ioup, 1984; Flege, 1987; White \& Genesee, 1996; Bongaerts, Van, Planken, 
\& Schils, 1997. The others hold that difference in achievements between early and late second language learner may result from education, use of L1 and L2, socio-psychological factors, L1-targetlanguage pairings, levels of education rather than maturational constraints, similar argument can be found in the reports of Kellerman, (1995), Bialystok \& Hakuta (1999), Flege, Yeni-Komshian \& Liu (1999), Schumann (1978), Birdsong \& Molis (2001), McDonald (2000). In addition, late second language learners attain native-like accents, native-like proficiency or better achievements were taken as counterevidence against "the younger, the better" hypothesis.

Moreover, with the development of functional neuroimaging technologies, ERP, FMRI, and PET are introduced to examine the neurological dimensions of language processing and representation among early versus late second language learners, with a belief that late learners would process their second language in different brain areas compared to early learners. But again, similar to behavioral studies, different findings are far from consistent. Supportive evidences (i.e. partly different representations for different languages) are shown in the studies of Weber-Fox and Neville (1996), Kim, Relkin, Lee, and Hirsch (1997), Weber-Fox and Neville (1999), Wartenburger et al. (2003), while there is no evidence that languages are represented in distinct brain regions in the studies by Hurford and Kirby (1999), Chee, Tan, and their group (1999).

\section{Critical thinking of the ongoing arguments about "the younger, the better" hypothesis}

The literature review above apparently indicates that neither the proponents nor the opponents can draw any conclusion (i.e. whether the younger the learners are, the better they will achieve in second language acquisition or not) approved by each other, which leads it an existing controversial topic in second language acquisition research field. With much careful reading and comparison, it is believed that a number of factors might be responsible for such inconsistent findings in studies on the age issue in second language acquisition.

\section{1 different concepts of age}

Age of arrival, and age of acquisition were sometimes adopted in different studies to approve or disapprove "the younger, the better" hypothesis, which would lead to the totally different subject selection and be difficult to make comparisons across the different studies. For example, in the early studies by Asher \& Garcia, by Ramsey \& Wright by Oyama age of arrival (AoA) was taken for subject selection. Instead, age of acquisition (AOA) was accepted in other studies by Birdsong, by Bialystok \& Miller, by Bongaerts and his colleagues respectively; Besides, age of exposure (AoE) or Length of residence (LoR) were used in some of the similar studies on this topic.

\section{2 different aspects of language}

The aspects of language to be compared varied from phonology to morphology to syntax, and to different subparts of language: listening, speaking, reading, and writing.

Since phonology is the most examinable finite subsystem of a language, it has been a predominant focus to examine whether "the younger, the better" in second language acquisition, Snow \& Hoefnagel-Hohle (1978), Neufeld (1977, 1979), Williams (1980), Ioup et al. (1994), Bongaerts et al.(1995), McClelland(1998), Bongaerts(1999) focused their research interests in phonology in second language acquisition.

In terms of morphology and syntax, Patkowski (1980) carried out research on syntactic rating among highly educated immigrants to the United States. Johnson \& Newport (1989), Birdsong (1992) and Jia (1999) respectively investigated grammaticality judgment tasks by Chinese and Korean ESL learners, native English French learner and immigrants to the United States. Marinova-Todd (2003) recruited post-pubescent English learners of various first languages to finish tasks covering pronunciation, morphosyntax, lexical knowledge and language use. The multi-task in Birdsong's study (2005) to adult Anglophone learners of French included pronunciation and morphosyntax; Another study of immigrant to Sweden conducted by Hyltenstam in 1992 focused on grammar errors. 
Besides, Durette (1972) used a standardized test covering listening, speaking, reading and writing for American French learners. Swain (1981) tested English-speaking pupils in a late French immersion program in a French reading comprehension and listening comprehension test. Lasagabaster and Doiz (2003) analyzed the written production by bilingual students in English as a foreign language.

It is apparently illogical to take any finding (either supporting or opposing "the younger, the better" hypothesis) from one aspect of second language as the evidence for the other aspects of second language, not to say as the evidence for second language acquisition.

\subsection{Different points of observing}

In the literature different observing points were set for studies, from short-term classroom training course to long-term immigrant immersion program, which makes it hard to make any comparison between studies, even more difficult to achieve consensus of opinion on the issue of whether "the younger, the better" or not.

Only after ten 15-25 minute taped sessions, Olson and Samuels (1973) tried to explore possible differences in German pronunciation among English elementary pupils, junior and college students. Some English-speaking Canadians were sampled in Neufeld's study (1978) to observe their Chinese and Japanese pronunciation after intensive 12-hour training session. Ekstrand (1976) collected data in pronunciation and listening by some Swedish English learners in FLES programs after 18 weeks' of instruction. Dunkel and Pillet (1972) reported some differences in French grammar between American elementary \& secondary pupils after learning French for one year. In a well-known study by Burstall (1977), French listening, speaking, reading and writing by British French learners were test at age 11 and at age 16 .

Even if the result of any short-term training course confirms the hypothesis of "the younger, the better" in second language acquisition, no one knows whether such "better" can extend to their further second language learning or not. On the other hand, even if some finding were presented against the "the younger, the better" hypothesis from long-term immigrant immersion program, there is no introduction about how the other most influential factors in second language learning were controlled.

\subsection{Different methods of measurement}

A variety of language measures were used for the study and discussion of "the younger, the better" in second language acquisition, including pronunciation ratings for phonology, grammatical judgment tasks, assessment of tape-recorded interviews or assessment of written transcripts of spoken interviews

The large-scale study by Oyama (1976) aimed to examine the pronunciation of immigrants to the United States, using a 5-point scale to judge the "nativeness" of their accents during a reading-aloud task and during free speech. Piper and Cansin (1988) chose some advanced ESL learners in Canada as subjects to participate in an individual interview, read a short story aloud, and retell a personal narrative, native speaker judgments based on a 5-point scale were gathered for statistic. In Thompson's investigation (1991), a 5-point scale judgment was designed for three different samples of spoken English by Russian-born migrants settling in the United States as two native speakers of English checked the degree of foreign accent. Nikolov (2000) reported adult Hungarian learners with different first languages, the native-like accent was judged by three groups of native Hungarian speakers.

Bialystok and Miller (1999) examined syntax acquisition by Spanish speakers and Chinese speakers acquiring English, a grammaticality judgment task was used for measurement, his study findings dispute any role played by maturational constraints in second language acquisition. Mayo (2003) dwelt with the issue of grammaticality judgments by bilingual (Basque/Spanish) learners of different age groups in an EFL setting, indicating that the earlier starters did not perform better in a situation of foreign language environment. A grammaticality judgment test was introduced in 
Urponen's study (2004) to investigate Finnish women learning English as a second language, saying that the apparent significant predictors were ages of onset of EFL learning.

Ioup et al (1994) sampled advanced native speakers of English, measured their performance in Egyptian Arabic with tape-recorded spontaneous speech samples. In Neufeld's training investigation (1977) with 20 English-speaking Canadian participants to pronounce Chinese and Japanese words, after an intensive 12-hour training session in a lab setting, participants' final imitation of each phrase was recorded for analysis.

Generally, in pronunciation ratings for phonology, the longer and less constrained the speech sample to be judged, the more sharply foreign accents were noted by judges; and pronunciation imitation after intensive training cannot represent the subjects' real proficiency. As for grammatical judgment tasks (tests), concerns about the reliability of tasks as a measurement may somewhat undermine the conclusions, as Flynn and Manuel ever commented that "grammaticality judgment task results in themselves are notoriously difficult to interpret. While experiments often interpret such judgments as grammaticality judgments, it is difficult to know when it is the case for the subjects that grammar, but not some other factors (semantic or pragmatic), provides the basis for a judgment" (1991: 133).

\section{Suggestions}

Based on the literature review, a need become evident for the differentiation of the similar and different evidences for "the younger, the better" hypothesis in second language acquisition. It can't be taken for granted to accept or refuse any findings of "the younger, the better" hypothesis due to the fact that different concepts of age, different aspects of language, different points of observing, different methods of measurement have been employed in various studies concerned. It is predictable that "the younger, the better" hypothesis will continue to be a topic full of argument and controversy before a more logical and workable design appear. Personally, a more rational paradigm for this topic needs to take the following items into consideration: a clear and appropriate definition of age (factor); a large scale of participants chosen with rational criteria is needed; same instruments of measurement for participants to be compared; the evaluation of the learning achievements should be scientific and objective; a combining exploration of the short-, mid- and long-term achievements in a study is necessary, even the achievements of subparts of a second language if possible; any study on age effects should bear reexamination and make duplicate study possible.

\section{References}

[1] E. Bialystok, On the reliability of robustness: A reply to DeKeyser. Studies in Second Language Acquisition, vol.24, pp.481-88, 2002.

[2] D. Birdsong, Introduction: Whys and why nots of the critical period hypothesis. In D. Birdsong (Ed.), Second Language Acquisition and the Critical Period Hypothesis, pp. 1-22, Mahwah, NJ: Erlbaum, 1999.

[3] C. Burstall, Primary French in the balance. Foreign Language Annals, vol.10, pp. 245-52, 1977.

[4] R. Ellis, The Study of Second Language Acquisition. New York: Oxford University Press, 1994.

[5] J. E. Flege, Age of learning and second-language speech. In D. Birdsong (Ed.), Second Language Acquisition and the Critical Period Hypothesis (pp. 101-131). Mahwah, NJ: Erlbaum, 1999.

[6] G. Ioup, E. Boustagui, M. El Tigi, \& M. Moselle, Reexamining the critical period hypothesis: A case study of successful adult SLA in a naturalistic environment. Studies in Second Language Acquisition, vol.16, pp. 73-98, 1994.

[7] J. Johnson, \& E. L. Newport, Critical period effects in second language learning: The influence of maturational state on the acquisition of English as a second language. Cognitive Psychology, vol.21, pp. 60-99, 1989. 
[8] E. Lenneberg, Biological Foundations of Language. New York: Wiley, 1967.

[9] M. Long, Problems with supposed counter-evidence to the critical period hypothesis. International Review of Applied Linguistics, vol.43, pp. 287-317, 2005.

[10]M. S. Patkowski, Age and accent in a second language: A reply to James Emil Flege. Applied Linguistics, vol.11, pp.73-89, 1990.

[11]W. Penfield, \& L. Roberts, Speech and Brain Mechanisms. Princeton: Princeton University Press, 1959.

[12]D. M. Singleton, \& Z. Lengyel (Eds.), The age factor in second language acquisition: A critical look at the Critical Period Hypothesis. Clevedon, Avon: Multilingual Matters Ltd, 1995. 